\title{
Detecting Chlamydia trachomatis by direct immunofluorescence using a Cytobrush sampling technique
}

\author{
R A CIOTTI,* S J SONDHEIMER,* I NACHAMKIN $\dagger$ \\ From the *Family Planning Clinic, Department of Obstetrics and Gynecology, and the †Department of \\ Pathology and Laboratory Medicine, University of Pennsylvania School of Medicine, Philadelphia, USA
}

SUMMARY We compared two different methods of collecting endocervical samples for examination by direct immunofluorescence for Chlamydia trachomatis. A cervical Cytobrush gave better results than a dacron swab. Further studies should be performed to assess the value of alternative sampling methods to detect this organism.

Chlamydiae are now commonly detected in genital tract specimens in routine diagnosis by direct immunofluorescence. Direct immunofluorescence is as sensitive and specific as conventional culture.' Studies in our laboratory also suggest that direct immunofluorescence may be a valuable test for cure. ${ }^{2}$

One of the problems encountered with direct immunofluorescence, as with culture, is the need for proper specimen collection and the ability to obtain endocervical cells for analysis. ${ }^{3}$ Phillips and colleagues found that the number of cells present on the slide affected the direct immunofluorescence test results, and improved sensitivity was found when more endocervical cells were present. ${ }^{4} \mathrm{~A}$ swab is generally used to collect cervical material for analysis with direct immunofluorescence. Another device, the cervical Cytobrush (International Cytobrush, Hollywood, Florida, USA), has been used successfully at this school of medicine for performing Papanicolau smears and has also been found by Ros et al to be superior to swab collection of endocervical cells for cytopathological analysis. ${ }^{5}$ Because of its abrasive surface, the Cytobrush might also be better at disrupting the infected cells present in cervical secretions and thus improve chlamydial detection. As part of studies of chlamydial infections in our family planning clinic, ${ }^{2}$ we studied the use of the Cytobrush as a collection device for diagnosing chlamydial infection, and we compared it with swab collection.

\footnotetext{
Address for reprints: Dr I Nachamkin, Department of Pathology and Laboratory Medicine, Hospital of the University of Pennsylvania, 3400 Spruce Street, Philadelphia, PA 19104-4283, USA
}

Accepted for publication 4 January 1988

\section{Patients and methods}

We studied women aged 15 to 19 who attended the family planning clinic of the hospital of the University of Pennsylvania for routine gynaecological examination. In the first phase of the study, samples for chlamydial detection were collected using the MicroTrak collection device (MicroTrak, Syva Company, Palo Alto, California). This collection kit contains a glass slide for smear preparation, a dacron swab for sample collection, and fixative. In the second phase of the study, a Cytobrush (International Cytobrush, catalogue No 166100) was substituted for the dacron swab. The Cytobrush has a plastic shaft with nylon bristles arranged in a spiral at one end. In both phases, we collected endocervical cells in an identical fashion.

Statistical analysis of data was performed using Yate's corrected $\chi^{2}$ analysis.

\section{Results}

In phase one of this study, of 103 consecutive samples taken using the MicroTrak swab as the collection device, $73(71 \%)$ contained sufficient endocervical material for analysis. In phase two $88(63 \%)$ of 139 patients sampled with the Cytobrush yielded adequate samples for analysis. The difference between the sampling efficiency of each group was not significant $\left(\chi^{2} \mathrm{c}=1 \cdot 197 ; \mathrm{p}<0.3\right)$.

The table summarises the results of direct immunofluorescent of the adequate samples from both phases of the study. In phase one the percentage of positive samples was $12 \%$ compared with $27 \%$ in 
Table Detection of Chlamydia trachomatis in 161 endocervical samples using two different collection devices

\begin{tabular}{lccc}
\hline & \multicolumn{3}{c}{ Direct } \\
\cline { 2 - 4 } Method of collection & Positive & Negative & Total \\
\hline MicroTrak swab & 9 & 64 & 73 \\
Cytobrush & 24 & 64 & 88 \\
Total & 33 & 128 & 161 \\
\hline
\end{tabular}

phase two. The difference in detection in the two phases was significant $\left(\chi^{2} \mathrm{c}=4.61 ; \mathrm{p}<0.05\right)$.

\section{Discussion}

We found that the use of the Cytobrush more than doubled the detection of chlamydiae. This increase, however, did not appear to be caused by an overall improvement in sample adequacy, as the proportions of negative results in both phases of the study were similar $(88 \%$ in phase one, $73 \%$ in phase two). Sampling with the brush was possibly better, though we did not count the number of endocervical cells present on the slides to make this comparison. The Cytobrush is more abrasive than a dacron swab and may have caused greater disruption of infected cells, thus improving positivity.

Although this was not a randomised study and the number of patients studied was relatively small, we do not believe that the different positivity in the two phases can be attributed to differences in the population or to a spontaneous increase in chlamydial infection. Both groups of patients were of the same socioeconomic class and age as those routinely seen for gynaecological examination. During the same period as the study, the overall clinic incidence of gonococcal infection was similar (4\% in both phases). In addition, the incidence of gonococcal infection was similar $(6 \%)$ in each group of patients.

Although the brush appeared to improve chlamydial detection, we did encounter problems with its use. In general, we rejected more samples obtained with the Cytobrush than with the swab because of the presence of gross blood. In addition, cervical bleeding was more a problem with the brush than with the swab device. On occasion, however, positive samples may be detected in the presence of gross blood. Under this circumstance, the results should be reported as being positive and are acceptable for evaluation.

Our findings suggest that additional randomised studies should be performed to assess the usefulness of the Cytobrush in improving the diagnosis of chlamydial infection.

\section{References}

1 Chernesky MA, Mahony JB, Castriciano S, et al. Detection of Chlamydia trachomatis antigens by enzyme immunoassay and immunofluorescence in genital specimens from symptomatic and asymptomatic men and women. $J$ Infect Dis 1986;154: $141-8$.

2 Nachamkin I, Sawyer K, Skalina D, Crooks GW, Ciotti R, Sondheimer SJ. Test-of-cure analysis by direct immunofluorescence for Chlamydia trachomatis after antimicrobial therapy. J Clin Microbiol 1987;25:1774-5.

3 Stamm WE, Holmes KK. Chlamydia trachomatis infections of the adult. In: Holmes KK, Mårdh P-A, Sparling PF, Wiesner PJ, eds. Sexually transmitted diseases. New York: McGraw Hill, 1984:258-70.

4 Phillips RS, Hanff PA, Kauffman RS, Aronson MD. Use of a direct fluorescent antibody test for detecting Chlamydia trachomatis cervical infection in women seeking routine gynecologic care. J Infect Dis 1987;156:575-81.

5 Ros E, Ayala MJ, Vilaplana E, et al. New technique for endocervical cytological sampling with Stormby's brush. Preliminary results. Citologia 1983;3:9-20. 
AIDS were positive for antibodies to HIV-I compared with only $1 / 27$ wives of seronegative controls. ${ }^{2}$ Another study undertaken in Kinshasa showed that of 3000 couples tested, in 80 cases the male partner was infected, and in only $20 / 80(25 \%)$ cases were both spouses infected. ${ }^{3}$ The high rate of infectivity in the first Zaïrian study was probably because all the men had AIDS, whereas in the second study, as well as in ours, the subjects were clinically healthy.'

The incidence of heterosexual transmission that we report in the present survey is higher than in wives of men infected through blood products. Several hypotheses may explain this finding. In Africa, chronic stimulation of the immune system is more common than in American heterosexuals, thus possibly increasing the number of target cells that the virus can infect." More specifically, the high prevalence of sexually transmitted diseases in Africa, particularly genital ulcers, may facilitate the transmission of HIV. ${ }^{15}$ Finally, young African women may be more sexually active and thus at increased risk of infection.

This study highlights the need for prospective studies to assess more accurately the efficiency of heterosexual transmission of HIV and the possible role of cofactors in the spread of the disease.

$$
\begin{array}{r}
\text { Yours faithfully, } \\
\text { L Bélec } \\
\text { A J Georges } \\
T \text { Brogan } \\
G \text { Steenman } \\
\text { M C Georges-Courbot } \\
P M V \text { Martin }
\end{array}
$$

Institut Pasteur de Bangui, BP 923, BANGUI, Central African Republic

\section{References}

1 Padian NS. Heterosexual transmission of acquired immunodeficiency syndrome: international perspectives and national projections. Rev Infect Dis 1987;9:947-60.

2 Mann JM, Quinn TC, Francis H, et al. Prevalence of HTLV-III/LAV in household contacts of patients with confirmed AIDS and controls in Kinshasa, Zaire. JAMA 1986;256:721-4.

3 Africa: vaginal sex inefficient in transmitting HIV. CDC Aids Weekly 1988; April 4:4.

4 Quinn TC, Piot P, McCormick JB, et al. Serologic and immunologic studies in patients with AIDS in north America and Africa. The potential role of infectious agents as cofactors in human immunodeficiency virus infection. JAMA 1987;257:2617-21.

5 Kreiss JK, Koech D, Plummer FA, et al. AIDS virus infection in Nairobi prostitutes: spread of the epidemic to east Africa. $N$ Engl J Med 1986;314:414-8.

\section{Notices}

First congress of the European Academy of
Dermatology and Venereology

The first congress of the European Academy of Dermatology and Venereology, for continuing education, will be held on 25-28 September 1989.

Topics will include: AIDS and dermatologists, what's new in treatment, dermatological surgery, warts and viruses, cutaneous histopathology, cutaneous immunopathology, and contact dermatitis.

For further information, please contact Centro Servizio Segreteria, EADV, Via Lapini 1, 50136 Florence, Italy.
Conference on vaccines for sexually transmitted diseases

A conference on vaccines for sexually transmitted diseases will be held on 5-7 April 1989 at Oxford University. It is sponsored by the journal, Vaccine, and the World Health Organisation.

For further information, please contact DE Cogan, Vaccines for Sexually Transmitted Diseases, Butterworth Scientific Ltd, PO Box 63, Westbury House, Bury Street, Guildford, Surrey, GU2 5BH (Tel. 0483 300966). 8th Meeting of the International Society for Sexually Transmitted Disease Research (ISSTDR)

The 8th meeting of the ISSTDR will be held on 10-13 September 1989 in Copenhagen, Denmark.

For further information please contact the meeting organisers: DIS Congress Service, Linde Allé 48, DK-2720 Vanløse, Copenhagen, Denmark or the scientific secretariat (Mrs Sandra Hyman), Statens Seruminstitut, Neisseria Department, DK-2300 Copenhagen S, Denmark.

\section{Correction}

Detecting Chlamydia trachomatis by direct immunofiuorescence using a Cytobrush sampling technique (August 1988;64:245-6)

We regret that an error occurred in the above paper. The second sentence of the first paragraph should have read:

"Direct immunofluorescence is adequately sensitive and specific compared with conventional culture." 